\title{
Impacts of cloud heterogeneities on cirrus optical properties retrieved from space-based thermal infrared radiometry
}

\author{
T. Fauchez ${ }^{1}$, P. Dubuisson ${ }^{1}$, C. Cornet ${ }^{1}$, F. Szczap ${ }^{2}$, A. Garnier ${ }^{3,4}$, J. Pelon ${ }^{5}$, and K. Meyer ${ }^{6,7}$ \\ ${ }^{1}$ Laboratoire d'Optique Atmosphérique, Université Lille 1, Villeneuve d'Ascq, France \\ ${ }^{2}$ Laboratoire de Météorologie Physique, Université Blaise Pascal, Clermont Ferrand, France \\ ${ }^{3}$ Science Systems and Applications, Inc., Hampton, Virginia, USA \\ ${ }^{4}$ NASA Langley Research Center, Hampton, Virginia, USA \\ ${ }^{5}$ Laboratoire Atmosphères, Milieux, Observations Spatiales, UPMC-UVSQ-CNRS, Paris, France \\ ${ }^{6}$ Goddard Earth Sciences Technology and Research (GESTAR), Universities Space Research Association, \\ Columbia, Maryland, USA \\ ${ }^{7}$ NASA Goddard Space Flight Center, Greenbelt, Maryland, USA \\ Correspondence to: C. Cornet (celine.cornet@univ-lille1.fr)
}

Received: 20 May 2014 - Published in Atmos. Meas. Tech. Discuss.: 27 August 2014

Revised: 2 January 2015 - Accepted: 12 January 2015 - Published: 9 February 2015

\begin{abstract}
This paper presents a study, based on simulations, of the impact of cirrus cloud heterogeneities on the retrieval of cloud parameters (optical thickness and effective diameter) for the Imaging Infrared Radiometer (IIR) on board CALIPSO. Cirrus clouds are generated by the stochastic model 3DCLOUD for two different cloud fields and for several averaged cloud parameters. One cloud field is obtained from a cirrus observed on 25 May 2007 during the airborne campaign CIRCLE-2 and the other is a cirrus uncinus. The radiative transfer is simulated with the $3 \mathrm{DMCPOL}$ code. To assess the errors due to cloud heterogeneities, two related retrieval algorithms are used: (i) the split-window technique to retrieve the ice crystal effective diameter and (ii) an algorithm similar to the IIR operational algorithm to retrieve the effective emissivity and the effective optical thickness. Differences between input parameters and retrieved parameters are compared as a function of different cloud properties such as the mean optical thickness, the heterogeneity parameter and the effective diameter. The optical thickness heterogeneity for each $1 \mathrm{~km} \times 1 \mathrm{~km}$ observation pixel is represented by the optical thickness standard deviation computed using $100 \mathrm{~m} \times 100 \mathrm{~m}$ subpixels. We show that optical thickness heterogeneity may have a strong impact on the retrieved parameters, mainly due to the plane-parallel approximation (PPA assumption). In particular, for cirrus clouds with ice crystal diameter of approximately $10 \mu \mathrm{m}$, the averaged er-
\end{abstract}

ror on the retrieved effective diameter and optical thickness is about $2.5 \mu \mathrm{m}(\sim 25 \%)$ and $-0.20(\sim 12 \%)$, respectively. Then, these biases decrease with increasing effective size due to a decrease of the cloud absorption and, thus, the PPA bias. Cloud horizontal heterogeneity effects are greater than other possible sources of retrieval errors such as those due to cloud vertical heterogeneity impact, surface temperature or atmospheric temperature profile uncertainty and IIR retrieval uncertainty. Cloud horizontal heterogeneity effects are larger than the IIR retrieval uncertainty if the standard deviation of the optical thickness, inside the observation pixel, is greater than 1.

\section{Introduction}

In the context of global climate change, the representation and role of clouds are still uncertain. For example, ice clouds play an important role in the climate and on the Earth's radiation budget (Liou, 1986). Cirrus clouds lead mainly to a positive radiative forcing due to their high temperature contrast with respect to the surface. However, the cirrus radiative forcing could depend on the cirrus optical thickness, altitude and ice crystal effective size (Katagiri et al., 2013). Consequently, to improve our knowledge, it is essential to assess the feedback and climate effects of these clouds (Stephens, 
1980). Global satellite observations are well suited to monitoring and investigating cloud evolution and characteristicsm because passive top-of-atmosphere (TOA) radiometric measurements allow for retrievals of cloud properties such as optical thickness and ice crystal effective diameter. In this work, we focus on infrared measurements obtained by the Imaging Infrared Radiometer (IIR; Garnier et al., 2012, 2013) onboard the Cloud-Aerosol Lidar and Infrared Pathfinder Satellite Observations (CALIPSO).

Because of operational constraints (lack of information regarding the 3-D structure of the atmosphere, time constraints, etc.), satellite-based cloud retrieval algorithms assume that clouds are homogeneous and infinite between two planes. This assumption of 1-D radiative transfer is called the homogeneous independent pixel approximation (Cahalan et al., 1994) or independent column approximation (Stephens et al., 1991). However, in a real atmosphere, clouds have 3-D structures, i.e, horizontal and vertical heterogeneities and the simplified 1-D atmosphere assumption may lead to biased cloud property retrievals (Fauchez et al., 2014). Many studies have been conducted to determine the impact of cloud heterogeneities on cloud products derived from solar spectral measurements. These studies primarily focused on warm clouds such as stratocumulus (Varnai and Marshak, 2001; Zinner and Mayer, 2006; Kato and Marshak, 2009, etc.) and showed that the sign and amplitude of retrieval errors depend on numerous factors, such as the spatial resolution, wavelength, geometry of observation and cloud morphology. Concerning cirrus clouds, Fauchez et al. (2014) showed that cirrus cloud heterogeneities lead to non-negligible effects on brightness temperatures (BT) and that these effects mainly depend on the standard deviation of the optical thickness inside the observation pixel. The retrieval of cloud properties using radiances or BT may thus be impacted by the heterogeneity effects. In this work, we extend the study of Fauchez et al. (2014) to investigate the impacts of cirrus heterogeneities on cloud optical property (optical thickness and ice crystal effective size) retrievals using simulations of radiometric measurements of IIR in three typical spectral bands, namely 8.65 , 10.60 and $12.05 \mu \mathrm{m}$.

In the thermal infrared atmospheric window $(8-13 \mu \mathrm{m})$, cloud optical properties (optical thickness and ice crystal effective size) are retrieved using the split-window technique (SWT) (Inoue, 1985; Parol et al., 1991; Dubuisson et al., 2008). This method is generally limited to thin cirrus clouds (optical thickness less than approximately 3 at $12 \mu \mathrm{m}$ ) and small crystals (effective diameters smaller than approximately $40 \mu \mathrm{m}$ ). In the visible and near-infrared spectra, cloud optical properties are commonly retrieved using the Nakajima and King method (Nakajima and King, 1990) that combines measurements in visible and near-infrared channels for optically thicker cirrus clouds and larger ice crystals. Cooper et al. (2007) combined these two methods for MODIS measurements to treat thin and thick cirrus simultaneously.
The paper is organized as follows. In Sect. 2, we present a short description of the modeling tools used in this study: (i) the cloud generator 3DCLOUD (Szczap et al., 2014), (ii) the radiative transfer code 3DMCPOL (Cornet et al., 2010; Fauchez et al., 2014) and (iii) two related retrieval algorithms. In Sect. 3, we present possible retrieval errors due to the 1-D approximation. In Sect. 4, we compare heterogeneity effects with other possible error sources considered in this paper such as those due to cloud vertical heterogeneity, surface temperature or atmospheric temperature profile uncertainty, as well as the IIR retrieval uncertainty. Conclusions and perspectives are given in Sect. 5.

\section{Numerical models}

\subsection{3-D ice water content generation}

The stochastic model 3DCLOUD (Cornet et al., 2010; Szczap et al., 2014) is employed to generate realistic 3D cirrus clouds. This model uses a simplified dynamical and thermodynamical approach to generate heterogeneous 3-D clouds as well as a Fourier transform framework to constrain scale invariant properties (Hogan and Kew, 2005; Szczap et al., 2014). Two different cirrus fields were simulated (Fig. 1) in a mid-latitude summer (MLS) atmosphere.

The first cirrus field has been modeled from meteorological profiles presented by Starr and Cox (1985) coupled with a wind profile to form virgas. The cloud layer is defined by the mean optical thickness $\tau_{\mathrm{c}}$, the standard deviation of the optical thickness on the entire field $\sigma_{\tau_{\mathrm{c}}}$, the cirrus heterogeneity parameter $\rho_{\tau}=\sigma_{\tau_{\mathrm{c}}} / \tau_{\mathrm{c}}$ (Szczap et al., 2000) and the ice crystal effective diameter $D_{\text {eff }}$ for an aggregate crystal shape (Yang et al., 2005). $D_{\text {eff }}$ is defined as

$D_{\text {eff }}=\frac{3}{2} \frac{\int V(L) n(L) \mathrm{d} L}{\int A(L) n(L) \mathrm{d} L}$,

where $L$ is the maximum crystal size, $V(L)$ is the volume of the crystal, $A(L)$ is the projected area and $n(l)$ is the size distribution (Yang et al., 2000).

Eight cirrus clouds are generated (Table 1) by varying the above parameters to cover the characteristics of typical cirrus clouds (Sassen and Cho, 1992; Szczap et al., 2000; Carlin et al., 2002; Lynch et al., 2002). Note that the effective diameter of cirrus cases 3 to $5\left(D_{\text {eff }}=9.95 \mu \mathrm{m}\right)$ is probably too small for cirrus with a mean optical thickness of 1.80 because aggregations processes tend to increase the effective size (Fig. 12 of Garnier et al., 2013). Cloud heterogeneity effects are probably slightly overestimated due to the too-small crystal effective size (heterogeneity effects are larger for small effective sizes) with respect to the mean cirrus optical thickness. Nevertheless, cirrus cases 3 to 5 are useful for understanding how heterogeneity effects increase with the optical thickness heterogeneity parameter $\left(\rho_{\tau}\right.$ in Table 1), which increases from 0.7 to 1.1 and 1.5 with other 



Figure 1. Top figures: Cirrus generated from realistic meteorological conditions (Starr and Cox, 1986; Hogan and Kew, 2005) with (a) the $10 \mathrm{~km} \times 10 \mathrm{~km}$ optical thickness field simulated at $12.05 \mu \mathrm{m}$ with a horizontal spatial resolution of $100 \mathrm{~m}$ and (b) the $x-z$ view through the red line of (a) of the cirrus IWC with a vertical spatial resolution of $58 \mathrm{~m}$. Bottom figures: CII cirrus simulation based on optical and microphysical properties of the cirrus observed during the CIRCLE-2 campaign on 25 May 2007: (c) the $20 \mathrm{~km} \times 20 \mathrm{~km}$ optical thickness field at $12.05 \mu \mathrm{m}$, with a horizontal spatial resolution of $100 \mathrm{~m}$ and with a mean optical thickness $\tau_{\mathrm{c}}=0.41$ observed by IIR at $12.05 \mu \mathrm{m}$, and (d) the $x-z$ view through the red line of (c) the cirrus IWC with a vertical resolution of $58 \mathrm{~m}$.

cloud properties held constants. Two cirrus cloud cases are presented in Fig. 1. The first cloud structure is presented in Fig. 1a and b. Figure 1a presents the $10 \mathrm{~km} \times 10 \mathrm{~km}$ optical thickness field at $12.05 \mu \mathrm{m}$ with a spatial resolution of $100 \mathrm{~m}$, and Fig. $1 \mathrm{~b}$ presents the $x-z$ view of the ice water content (IWC) of cirrus case 3 .

Figure $1 \mathrm{c}$ and d show cirrus generated from measurements obtained on 25 May 2007 during the CIRCLE-2 airborne campaign (Mioche et al., 2010). In situ measurements provided by the aircraft, as well as IIR radiometric measurements (mean optical thickness and mean heterogeneity parameter), are used as input for 3DCLOUD. In addition, meteorological data from the European Center for Medium-Range Weather Forecasts are used to constrain the meteorological profiles (wind speed and orientation, temperature, humidity, etc.). The scale invariant properties of every cirrus case presented in Table 1 are controlled by a constant spectral slope $(-5 / 3)$ for all scales and altitude levels. This agrees with the spectral slope of the backscattering coefficient measured at $532 \mathrm{~nm}$ at different altitudes by the Cloud-Aerosol Lidar with Orthogonal Polarization (CALIOP) on-board CALIPSO and the extinction coefficient measured by the polar nephelometer at the aircraft altitude (Fauchez et al., 2014).

\subsection{Optical property parametrization}

Cirrus optical properties are difficult to characterize because of the diversity of crystal sizes, shapes and orientations in a cirrus cloud. Several parametrizations were developed for visible and infrared wavelengths (Magono, 1966; Labonnote et al., 2000; Yang et al., 2001, 2005; Baum et al., 2005b, 2011; Baran and Labonnote, 2007; Baran et al., 2009; Baran, 2012; Baran et al., 2013). For cirrus cases 1 to 8 we employ the aggregate ice crystal model (Yang et al., 2001, 2005) with a monodisperse distribution used in the IIR retrieval algorithm (Garnier et al., 2013) that provides an extinction coefficient, a single-scattering albedo and an asymmetry factor (Yang et al., 2001, 2005). Note that Dubuisson et al. (2008) have shown that the IIR thermal infrared channels are weakly sensitive to the ice crystal shape and almost insensitive to the size distribution. The IIR retrieval algorithm uses three ice crystal shapes (Garnier et al., 2012, 2013), namely a solid column, aggregate and plate. The phase functions of these 
Table 1. Mean cloud properties of the cirrus generated by 3DCLOUD. "CTA" corresponds to the cirrus-top altitude; "OP" corresponds to the optical properties parametrization; "Yal" represents the model of ice crystals developed by Yang et al. (2001, 2005) for aggregates ice crystals; and "Bal" represents the parametrization of ice crystals' optical properties developed by Baran et al. (2009), Baran (2012), and Baran et al. (2013); $\tau_{\mathrm{c}}$ is the cloud mean optical thickness; $\sigma_{\tau}$ is the cloud standard deviation of the optical thickness estimated from the optical thickness of the subpixels at the scale of $100 \mathrm{~m} \times 100 \mathrm{~m} ; \rho_{\tau}$ is the cloud heterogeneity parameter defined as the ratio of $\sigma_{\tau}$ by $\tau_{\mathrm{c}}$; and $D_{\mathrm{eff}}$ is the ice crystal effective diameter.

\begin{tabular}{rrrrrrr}
\hline Cirrus & CTA $(\mathrm{km})$ & $\tau_{\mathrm{c}}$ & $\sigma_{\tau}$ & $\rho_{\tau}$ & $D_{\text {eff }}(\mu \mathrm{m})$ & OP \\
\hline 1 & 7.97 & 0.45 & 0.32 & 0.7 & 9.95 & Yal \\
2 & 7.97 & 0.90 & 0.63 & 0.7 & 9.95 & Yal \\
3 & 7.97 & 1.80 & 1.26 & 0.7 & 9.95 & Yal \\
4 & 7.97 & 1.80 & 1.98 & 1.1 & 9.95 & Yal \\
5 & 7.97 & 1.80 & 2.70 & 1.5 & 9.95 & Yal \\
6 & 7.97 & 1.80 & 1.26 & 0.7 & 20.09 & Yal \\
7 & 7.97 & 1.80 & 1.26 & 0.7 & 40.58 & Yal \\
8 & 11.06 & 0.90 & 0.63 & 0.7 & 9.95 & Yal \\
CII-1 & 11.06 & 0.41 & 0.32 & 0.77 & heterogeneous & Bal \\
CII-2 & 11.06 & 0.81 & 0.62 & 0.77 & heterogeneous & Bal \\
CII-3 & 11.06 & 0.90 & 0.63 & 0.70 & 9.95 & Yal \\
\hline
\end{tabular}

particles are relatively smooth in the thermal infrared with a small forward peak (asymmetry factor $g$ usually below 0.9 ) and can be approximated by the Henyey-Greenstein phase function. While this assumption is certainly problematic for irregular crystal shapes, as shown by Baum et al. (2005a, b), we use the Henyey-Greenstein phase function to remain consistent with the official IIR retrieval algorithm (Garnier et al., 2012, 2013). For these cirrus cases, the optical properties are constant over the entire cloud.

In order to generate 3-D and heterogeneous cloud optical properties fields for the CII- 1 and CII- 2 cirrus cases, we used the parametrization of Baran et al. $(2009,2013)$ and Baran (2012). This parametrization, derived from in situ measurements of more than 20000 particle-size distributions (Field et al., 2005, 2007), gives the optical coefficients as a function of IWC and temperature.

\subsection{TOA brightness temperature simulations}

TOA brightness temperatures in the three IIR thermal infrared channels $(8.65,10.60$ and $12.05 \mu \mathrm{m})$ are simulated with the 3DMCPOL code developed in the visible range by Cornet et al. (2010) and extended to the infrared range by Fauchez et al. (2014). 3DMCPOL is a forward Monte Carlo algorithm using the local estimate method (Marshak and Davis, 2005; Mayer, 2009) and is able to simulate radiances and brightness temperatures from the visible to the infrared range, including the polarization. The atmosphere is subdivided in voxels (3-D pixels), with a constant horizontal size $(\mathrm{d} x, \mathrm{~d} y)$ and a variable vertical size $(\mathrm{d} z)$. Each voxel is described by the extinction coefficient $\sigma_{\mathrm{e}}$, the single- scattering albedo $\varpi_{0}$, the phase function and the cloud temperature $T_{\mathrm{c}}$.

3-D BT are first simulated at $100 \mathrm{~m} \times 100 \mathrm{~m}$ spatial resolution and are then averaged to the IIR spatial resolution of $1 \mathrm{~km} \times 1 \mathrm{~km}\left(\mathrm{BT}_{1}^{3-\mathrm{Dm}}\right) .1$-D BT are obtained by averaging the optical property field to $1 \mathrm{~km} \times 1 \mathrm{~km}$ spatial resolution before simulating the $\mathrm{BT}\left(\mathrm{BT}_{1 \mathrm{~km}}^{1-\mathrm{D}}\right)$.

Note that the statistical uncertainty of these simulations is below $0.5 \mathrm{~K}$, which is less than the IIR accuracy of about $1 \mathrm{~K}$. Comparisons between 3DMCPOL statistical uncertainty, IIR accuracy and heterogeneity effects can be found in Fauchez et al. (2014) (Figs. 8 and 10) for the same cloud scenes. This statistical uncertainty is reached by simulating between 5 and 10 billion photons for each case.

\subsection{Retrieval algorithms of cloud parameters}

Two related algorithms are used to retrieve cloud products: the split-window technique (Inoue, 1985; Parol et al., 1991; Dubuisson et al., 2008) to retrieve the effective diameter and an algorithm similar to the IIR operational algorithm to retrieve the effective emissivity and the effective optical thickness.

In the thermal infrared atmospheric window, the SWT is one of the most used methods to retrieve the effective diameter and the cloud optical thickness using the difference of brightness temperatures between two thermal infrared channels (Parol et al., 1991; Radel et al., 2003; Dubuisson et al., 2008; Garnier et al., 2012, 2013). Figure 2 shows brightness temperature difference (BTD) for varying optical thickness (0-50 at $12.05 \mu \mathrm{m})$ and eight effective diameters $\left(D_{\text {eff }}\right)$ as a function of the $12.05 \mu \mathrm{m} \mathrm{BT}\left(\mathrm{BT}_{12}\right)$. Each "arch" corresponds to a single effective size, with BTD decreasing with increasing particle size and optical thickness decreasing along each arch from opaque cloud (low BT) to clear sky (high BT). It is evident that the sensitivity of the SWT to large particles $\left(D_{\text {eff }}>40 \mu \mathrm{m}\right)$ is weak, one of the main disadvantages of this method that can only accurately determine the effective size of particles smaller than approximately $40 \mu \mathrm{m}$ for cirrus clouds with an optical thickness approximately between 0.5 and 3 (Dubuisson et al., 2008; Sourdeval et al., 2012). Dubuisson et al. (2008) also show that the SWT retrieval accuracy for ice crystal effective diameter is between 10 and $25 \%$ and for the optical thickness is about $10 \%$. We note that the amplitude of the $\mathrm{BTD}_{8-10}$ arches is significantly smaller than the two others because its sensitivity to $D_{\text {eff }}$ is weaker. Consequently, this channel pair will not be used in this study.

Similar to the SWT, the IIR operational algorithm (Garnier et al., 2012) uses radiance differences between channels, though in a different way. Intermediate products (effective emissivity, effective optical thickness and microphysical indices) are computed to retrieve the ice crystal effective diameter and shape. The effective emissivity refers to the contribution of scattering in the retrieved emissivity, especially for 
small ice crystals in the band at $8.65 \mu \mathrm{m}$. One of the major advantages of using the effective emissivity is its independence of cloud-top altitude or geometrical thickness, contrary to the brightness temperature differences used in the SWT. The effective emissivity, $\varepsilon_{\mathrm{eff}, k}$, for the channel $k$ is defined as

$\varepsilon_{\mathrm{eff}, k}=\left[R_{k}-R_{k, \mathrm{BG}}\right] /\left[B_{k}\left(T_{\mathrm{c}}, Z_{\mathrm{c}}\right)-R_{k, \mathrm{BG}}\right]$,

where $R_{k}$ is the measured (or simulated) radiance in the channel $k, R_{k, \mathrm{BG}}$ is the measured (or simulated) radiance at TOA for clear sky and $B_{k}\left(T_{\mathrm{c}}, Z_{\mathrm{c}}\right)$ is the radiance of an opaque cloud (black body) located at the centroid altitude $Z_{\mathrm{c}}$ and at the centroid temperature $T_{\mathrm{c}}$, provided by the GEOS-5 model (Rienecker et al., 2008). The layer centroid altitude is a weighted average altitude based on the attenuated backscattered intensity of the LIDAR signal at $532 \mathrm{~nm}$ (Vaughan et al., 2009). Note that, in this study, we set the centroid altitude to the geometrical middle of the cloud.

The effective optical thickness $\tau_{\text {eff, } k}$ is then calculated as

$\tau_{\mathrm{eff}, k}=-\ln \left(1-\varepsilon_{\mathrm{eff}, k}\right)$.

From $\tau_{\text {eff, },}$, the microphysical indices $\mathrm{MI}^{12 / 8}$ and $\mathrm{MI}^{12 / 10}$ are defined as the ratio of $\tau_{\text {eff }, k}$ between 12.05 and $8.65 \mu \mathrm{m}$ channels and 12.05 and $10.60 \mu \mathrm{m}$ channels, respectively:

$\mathrm{MI}_{12 / 8}=\tau_{\mathrm{eff}, 12} / \tau_{\mathrm{eff}, 8}, \quad \mathrm{MI}_{12 / 10}=\tau_{\mathrm{eff}, 12} / \tau_{\mathrm{eff}, 10}$.

These microphysical indices strongly depend on the microphysical and optical properties of the cloud layer, namely the effective diameter and shape of the ice crystals. From a look-up table (LUT) of the microphysical indices as a function of the effective diameter and shape precalculated by the FASDOM code (Dubuisson et al., 2005), two values of effective diameters $\left(D_{\text {eff, } 1 \mathrm{~km}}(10,8)\right.$ and $\left.D_{\text {eff, } 1 \mathrm{~km}}(12,8)\right)$ are obtained for each particle shape (aggregates, plates and solid columns) considered in the IIR retrieval algorithm. The shape corresponding to the smallest difference between the two $D_{\text {eff, }} 1 \mathrm{~km}$ is selected. For the computation of optical properties, the IIR operational algorithm uses the Yang et al. (2001, 2005) model with a monomodal effective diameter distribution.

The uncertainty of the retrieval algorithm was checked by comparing optical properties retrieved from simulated radiances with the optical properties used as input in the radiative transfer. For this, we perform a 1-D retrieval from 1D-simulated radiances. The algorithm uncertainties are less than $2 \%$ for effective diameters retrieved with the SWT (test not shown here) and $4 \%$ for effective optical thickness retrieved with the algorithm similar to the IIR operational algorithm (test not shown here).

\section{Impact of cirrus heterogeneities on the retrieved parameters}

In this section, we present the heterogeneity effects on the retrieved products at the $1 \mathrm{~km}$ IIR spatial resolution as a function of different cloud optical properties (i.e., optical thickness, effective diameters, extinction coefficients, singlescattering albedo and asymmetry factor) and microphysical (IWC) properties, cirrus-top altitude and geometrical thickness. The heterogeneity effects on the retrieved parameters are assessed by using the difference between products retrieved from modeled 3-D $\left(\mathrm{BT}_{1 \mathrm{~km}}^{3-\mathrm{D}}\right)$ and 1-D $\left(\mathrm{BT}_{1 \mathrm{~km}}^{1-\mathrm{D}}\right) 1 \mathrm{~km}$ brightness temperatures.

In order to estimate the heterogeneity effects on the retrieved cloud products, we define the following errors due to cloud heterogeneities:

$\Delta \varepsilon_{\mathrm{eff}}=\varepsilon_{\mathrm{eff}}^{3-\mathrm{D}}-\varepsilon_{\mathrm{eff}}^{1-\mathrm{D}}$

for effective emissivities calculated by the Eq. (2);

$\Delta \tau_{\mathrm{eff}}=\tau_{\mathrm{eff}}^{3-\mathrm{D}}-\tau_{\mathrm{eff}}^{1-\mathrm{D}}$

for effective optical thicknesses calculated by Eq. (3);

$$
\begin{gathered}
\Delta \mathrm{MI}^{12 / 8}=\mathrm{MI}^{3-\mathrm{D}, 12 / 8}-\mathrm{MI}^{1-\mathrm{D}, 12 / 8} \text { and } \\
\Delta \mathrm{MI}^{12 / 10}=\mathrm{MI}^{3-\mathrm{D}, 12 / 10}-\mathrm{MI}^{1-\mathrm{D}, 12 / 10}
\end{gathered}
$$

for microphysical indices calculated from Eq. (4);

$\Delta D_{\text {eff, } 1 \mathrm{~km}}=D_{\text {eff, } 1 \mathrm{~km}}^{3-\mathrm{D}}-D_{\text {eff, } 1 \mathrm{~km}}^{1-\mathrm{D}}$

for ice crystal effective diameter retrieved with the SWT.

The "3-D" exponent corresponds to optical properties retrieved from $\mathrm{BT}_{1 \mathrm{~km}}^{3-\mathrm{D}}$ and the "1-D" exponent corresponds to those retrieved from $\mathrm{BT}_{1 \mathrm{~km}}^{1-\mathrm{D}}$. $D_{\text {eff, }}^{1-\mathrm{d}} \mathrm{km}$ corresponds either to the effective diameter used in the radiative transfer simulation when it is known (cirrus cases 1 to 8 and CII- 3 ) or to the effective diameter retrieved from $\mathrm{BT}_{1}^{1-\mathrm{Dm}}$ when the ice crystal effective diameters used in the radiative transfer simulation are unknown (cirrus cases CII-1 and CII-2).

Heterogeneity impacts due to the optical thickness variability are discussed in Sect. 3.1 and those due to optical and microphysical property variabilities in Sect. 3.2.

\subsection{Heterogeneity impacts due to the optical thickness variability}

Fauchez et al. (2014) show that $\mathrm{BT}_{1 \mathrm{~km}}^{3-\mathrm{D}}$ are larger than $\mathrm{BT}_{1 \mathrm{~km}}^{1-\mathrm{D}}$ and that their difference is well correlated with the standard deviation of the optical thickness inside the $1 \mathrm{~km} \times 1 \mathrm{~km}$ observation pixel $\sigma_{\tau_{1} \mathrm{~km}}$. This brightness temperature difference is due to the plane-parallel approximation caused by the non-linearity of the relationship between brightness temperature and optical thickness. The impact of the PPA bias $\left(\left|\mathrm{BT}_{1 \mathrm{~km}}^{3-\mathrm{D}}-\mathrm{BT}_{1 \mathrm{~km}}^{1-\mathrm{D}}\right|\right)$ is greater (in absolute value) for highly absorbing bands because the increase of cloud absorption leads to a larger brightness temperature contrast between the cirrus top and the clear sky atmosphere and, thus, to a stronger averaging effect. Figure 3 illustrates how cirrus heterogeneities affect the retrieval of the effective 



Figure 2. Brightness temperatures differences (BTD) as a function of the $12.05 \mu \mathrm{m}$ brightness temperature $\left(\mathrm{BT}_{12}\right)$ for eight effective diameters $\left(D_{\text {eff }}\right)$ and different optical thickness between 0 and 50 at $12.05 \mu \mathrm{m}$ : (a) $\mathrm{BTD}_{10-12}$ between 10.60 and $12.05 \mu \mathrm{m}$ channels, (b) BTD $_{8-12}$ between 8.65 and $12.05 \mu \mathrm{m}$ channels and (c) $\mathrm{BTD}_{8-10}$ between 8.65 and $10.60 \mu \mathrm{m}$ channels.
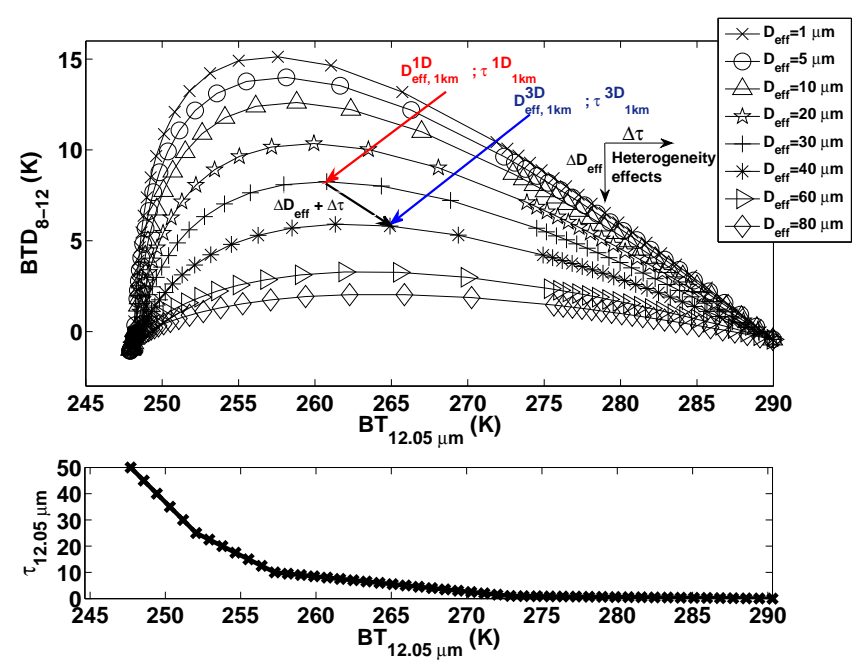

Figure 3. Top panel: brightness temperature differences between 8.65 and $12.05 \mu \mathrm{m}\left(\mathrm{BTD}_{12-8}\right)$ as a function of the brightness temperature at $12.05 \mu \mathrm{m}\left(\mathrm{BT}_{12}\right)$. The red arrow shows an example of effective diameter, $D_{\mathrm{eff}, 1 \mathrm{~km}}^{1-\mathrm{D}}$, and optical thickness, $\tau_{1 \mathrm{~km}}^{1-\mathrm{D}}$, retrieved in 1-D without heterogeneity effects, and the blue arrow shows the corresponding effective diameter, $D_{\text {eff, }}^{3-1 \mathrm{~km}}$, and optical thickness, $\tau_{1 \mathrm{~km}}^{3-\mathrm{D}}$, retrieved with heterogeneity effects. Each point of the arches corresponds to an optical thickness represented in the bottom panel, with $\tau_{12.05 \mu \mathrm{m}}$ as the optical thickness at $12.05 \mu \mathrm{m}$. Using the planeparallel approximation (PPA) leads to an overestimation of the effective diameter and to underestimation of the optical thickness, respectively, compared to a 3-D retrieval.

diameter and the optical thickness. The tip of the red arrow represents the BTD and BT values obtained with a homogeneous cloud with $D_{\text {eff, } 1 \mathrm{~km}}^{1-\mathrm{D}}$ and $\tau_{1 \mathrm{~km}}^{1-\mathrm{D}}$. Using 3-D radiative transfer inside a heterogeneous cloud with the same mean properties, we obtained the BTD and BT values represented by the tip of the blue arrow in Fig. 3. As heterogeneity effects are larger at the $12.05 \mu \mathrm{m}$ channel than at the $8.65 \mu \mathrm{m}$



Figure 4. Variation of the effective emissivity as a function of the effective optical thickness at $12.05 \mu \mathrm{m}$, estimated in 1-D at the spatial resolution of $100 \mathrm{~m}$ for the three IIR channels and for cloudy pixels belonging to cirrus cases 1 to 5 . $\tau_{\text {eff }}$ represents the effective optical thickness corresponding to the averaged effective emissivity $\overline{\varepsilon_{\text {eff }}}, \overline{\tau_{\text {eff }}}$ represents the averaged effective optical thickness and $\varepsilon_{\text {eff }}$ is its corresponding effective emissivity. Brown and green lines show the effective emissivity and effective optical thickness values on the $x$ axis and $y$ axis, respectively, corresponding to a particular point on, for instance, the black arch. The mathematical formulation of the PPA is expressed by the Jensen inequality $\overline{\varepsilon_{\text {eff }}}<\varepsilon_{\text {eff }}\left(\overline{\tau_{\text {eff }}}\right)$.

channel, brightness temperature differences $\left(\mathrm{BTD}_{8-12}\right)$, first simulated at the $100 \mathrm{~m}$ spatial resolution and then averaged to the $1 \mathrm{~km}$ IIR spatial resolution, are smaller than those retrieved from radiances directly simulated at $1 \mathrm{~km}$ spatial resolution. Consequently, as effective diameters increase with the decrease of BTD, the retrieved $D_{\text {eff, } 1 \mathrm{~km}}^{3-\mathrm{k}}$ is larger than the mean value $D_{\text {eff, } 1 \mathrm{~km}}^{1-\mathrm{D}}$ and the retrieved optical thicknesses $\tau_{1 \mathrm{~km}}^{3-\mathrm{D}}$ is smaller than the mean optical thickness $\tau_{1 \mathrm{~km}}^{1-\mathrm{D}}$.

In addition, Fig. 4 shows the effective emissivity as a function of the effective optical thickness estimated at $100 \mathrm{~m}$ spatial resolution. The relationship between effective emissivities and effective optical thickness is nonlinear, as it is between brightness temperatures and optical thickness. Because of the PPA bias, the average effective emissivity is smaller than the effective emissivity of the average of the effective optical thickness $\overline{\tau_{\text {eff }}}$. Similar to brightness temperatures, effective emissivities and effective optical thickness retrieved from radiances, first simulated at $100 \mathrm{~m}$ spatial resolution of and then averaged to the IIR spatial resolution of $1 \mathrm{~km}$, are smaller than those retrieved from radiances directly simulated at the spatial resolution of $1 \mathrm{~km}$.

Figure 5 presents $\Delta \varepsilon_{\text {eff }}\left(\mathrm{a}, \mathrm{b}\right.$ and $\mathrm{c}$ ) and $\Delta \tau_{\text {eff }}$ (d, e and f) as a function of the standard deviation of the optical thickness inside the $1 \mathrm{~km} \times 1 \mathrm{~km}$ observation pixel $\left(\sigma_{\tau_{1 \mathrm{~km}}}\right)$ for cirrus cases 1 to 5 and for $8.65,10.60$ and $12.05 \mu \mathrm{m}$ channels, respectively. We notice, first of all, that $\Delta \varepsilon_{\text {eff }}$ and $\Delta \tau_{\text {eff }}$ are correlated with $\sigma_{\tau_{1 \mathrm{~km}}}$ at more than $94 \%$ except for cirrus case 1 at $8.65 \mu \mathrm{m}$, where the horizontal transport smooths the slight 



Figure 5. Errors on the effective emissivity $\Delta \varepsilon_{\text {eff }}(\mathbf{a}, \mathbf{b}$ and $\mathbf{c})$ and on the effective optical thickness $\Delta \tau_{\text {eff }}(\mathbf{d}, \mathbf{e}$ and $\mathbf{f})$ at $8.65,10.60$ and $12.05 \mu \mathrm{m}$, respectively, as a function of the optical thickness standard deviation, $\sigma_{\tau_{1} \mathrm{~km}}$, for cirrus cases $1\left(\tau_{\mathrm{c}}=0.45, \rho_{\tau}=0.7\right), 2$ $\left(\tau_{\mathrm{c}}=0.90, \rho_{\tau}=0.7\right), 3\left(\tau_{\mathrm{c}}=1.80, \rho_{\tau}=0.7\right), 4\left(\tau_{\mathrm{c}}=1.80, \rho_{\tau}=1.1\right)$ and $5\left(\tau_{\mathrm{c}}=1.80, \rho_{\tau}=1.5\right)$ with $D_{\text {eff }}=9.95 \mu \mathrm{m}$ for the five cirrus. The black lines correspond to the IIR operational algorithm uncertainty on the effective emissivity.


Figure 6. Microphysical index differences $\Delta \mathrm{MI}^{12 / 8}$ (a) and $\Delta \mathrm{MI}^{12 / 10}$ (b) as a function of the standard deviation of the optical thickness, $\sigma_{\tau_{1 \mathrm{~km}}}$, for cirrus cases $1\left(\tau_{\mathrm{c}}=0.45, \rho_{\tau}=0.7\right), 2\left(\tau_{\mathrm{c}}=\right.$ $\left.0.90, \rho_{\tau}=0.7\right), 3\left(\tau_{\mathrm{c}}=1.80, \rho_{\tau}=0.7\right), 4\left(\tau_{\mathrm{c}}=1.80, \rho_{\tau}=1.1\right)$ and $5\left(\tau_{\mathrm{c}}=1.80, \rho_{\tau}=1.5\right)$ with $D_{\text {eff }}=9.95 \mu \mathrm{m}$ for the five cirrus. $R$ represents the correlation coefficient between $\Delta \mathrm{MI}$ and $\sigma_{\tau_{1 \mathrm{~km}}}$.

heterogeneity of the radiative field. $\Delta \varepsilon_{\text {eff }}$ and $\Delta \tau_{\text {eff }}$ are negative, meaning that the 3 -D effective emissivities and effective optical thickness are smaller than those in 1-D. Indeed, as explained by Fauchez et al. (2014), heterogeneity effects lead to an increase of radiances or brightness temperatures. As radiances decrease with the cloud extinction, larger radiances lead then to smaller cloud effective emissivity and effective optical thickness. In addition, $\Delta \varepsilon_{\text {eff }}$ and $\Delta \tau_{\text {eff }}$ are shown to depend on the wavelength. For example, at $\sigma_{\tau_{1 \mathrm{~km}}}=1, \Delta \varepsilon_{\text {eff }}$ is equal to -0.01 at $8.65 \mu \mathrm{m},-0.03$ at $10.60 \mu \mathrm{m}$ and -0.05 at $12.05 \mu \mathrm{m}$. This is due to the increase of absorption from 8.65 to $12.05 \mu \mathrm{m}$ that leads to an increase of the contrast between cloud and clear sky pixels, and thus to an increase of the PPA bias. For comparison, Garnier et al. (2012) have shown that



Figure 7. Errors on the retrieved effective diameter $\Delta D_{\text {eff, } 1 \mathrm{~km}}$ as a function of the standard deviation of the optical thickness, $\sigma_{\tau_{1 \mathrm{~km}}}$, for cirrus cases $1\left(\tau_{\mathrm{c}}=0.45, \rho_{\tau}=0.7\right), 2\left(\tau_{\mathrm{c}}=0.90, \rho_{\tau}=\right.$ $0.7), 3\left(\tau_{\mathrm{c}}=1.80, \rho_{\tau}=0.7\right), 4\left(\tau_{\mathrm{c}}=1.80, \rho_{\tau}=1.1\right)$ and $5\left(\tau_{\mathrm{c}}=\right.$ $\left.1.80, \rho_{\tau}=1.5\right)$ with $D_{\text {eff }}=9.95 \mu \mathrm{m}$ for the five cirrus. Effective diameters are estimated using the split-window technique.

the effective emissivity error due to the retrieval method is about 0.03 for the $12.05 \mu \mathrm{m}$ band (black lines of the Fig. 5) assuming a $1 \mathrm{~K}$ clear sky atmosphere temperature uncertainty for an ocean scene. This uncertainty is smaller than the average error due to cloud heterogeneity $\overline{\Delta \varepsilon_{\text {eff }}}$. We can note that, at $\sigma_{\tau_{1 \mathrm{~km}}} \sim 1, \Delta \varepsilon_{\text {eff }}$ is equal to or larger than 0.03 for the 10.60 and $12.05 \mu \mathrm{m}$ bands. $\sigma_{\tau_{1 \mathrm{~km}}} \sim 1$ corresponds also to the limit where the heterogeneity effects on brightness temperatures become larger than the IIR instrumental accuracy of $1 \mathrm{~K}$ (Fauchez et al., 2014). 



Figure 8. Errors on the effective emissivity $\Delta \varepsilon_{\text {eff }}(\mathbf{a}, \mathbf{b}$ and $\mathbf{c})$ and on the effective optical thickness $\Delta \tau_{\text {eff }}(\mathbf{d}, \mathbf{e}$ and $\mathbf{f})$ at $8.65,10.60$ and $12.05 \mu \mathrm{m}$, respectively, as a function of the optical thickness standard deviation, $\sigma_{\tau_{1 \mathrm{~km}}}$, for three identical cirrus fields but for different ice crystal effective diameters: cirrus cases $3\left(D_{\text {eff }}=9.95 \mu \mathrm{m}\right), 6\left(D_{\text {eff }}=20.09 \mu \mathrm{m}\right)$ and $7\left(D_{\text {eff }}=40.58 \mu \mathrm{m}\right)$, with $\tau_{\mathrm{c}}=1.80$ and $\rho_{\tau}=0.7$ for the three cirrus. R represents the correlation coefficient between $\Delta \varepsilon_{\text {eff }}(\mathbf{a}, \mathbf{b}$ and $\mathbf{c})$ and $\sigma_{\tau_{1} \mathrm{~km}}$ and between $\Delta \tau_{\text {eff }}(\mathbf{d}, \mathbf{e}$ and $\mathbf{f})$ and $\sigma_{\tau_{1} \mathrm{~km}}$.

Figure $6 \mathrm{a}$ and $\mathrm{b}$ show the error on the microphysical indices $\Delta \mathrm{MI}^{12 / 8}$ and $\Delta \mathrm{MI}^{12 / 10}$, respectively, as a function of $\sigma_{\tau_{1 \mathrm{~km}}}$ for cirrus cases 1 to 5 . First note that the errors on the two microphysical indices are on average negative, except again for cirrus case 1 for $\Delta \mathrm{MI}^{12 / 8}$, and they increase with the cirrus mean optical thickness (from cirrus cases 1 to 3 ) and heterogeneity parameter (from cirrus cases 3 to 5). The correlation with $\sigma_{\tau_{1 \mathrm{~km}}}$ is better for $\Delta \mathrm{MI}^{12 / 10}$ than for $\Delta \mathrm{MI}^{12 / 8}$. Again, the strongest scattering in the band at $8.65 \mu \mathrm{m}$ tends to smooth the radiative field heterogeneities and, therefore, to degrade the correlation between $\Delta \mathrm{MI}^{12 / 8}$ and $\sigma_{\tau_{1} \mathrm{~km}} . \Delta \mathrm{MI}^{12 / 8}$ is, on average, larger than $\Delta \mathrm{MI}^{12 / 10}$ because the difference of absorption and effective emissivity is significantly greater for the $12.05 \mu \mathrm{m} / 8.65 \mu \mathrm{m}$ pair than for $12.05 \mu \mathrm{m} / 10.60 \mu \mathrm{m}$. Effective diameters of ice crystals are estimated from the microphysical indices using a LUT and are thus also impacted by heterogeneity effects. As $\Delta \mathrm{MI}=\mathrm{MI}^{3-\mathrm{D}}-\mathrm{MI}^{1-\mathrm{D}}$ is negative, the impact of cloud heterogeneities leads to an underestimation of the microphysical indices. This underestimation leads then to an overestimation of the retrieved effective diameters (smaller microphysical indices correspond to larger effective diameters).

Using the SWT, we are also able to simulate the impact of cirrus heterogeneities on the retrieved effective diameters of ice crystals. In Fig. 7, we plot the error on the effective diameter error $\Delta D_{\text {eff, } 1 \mathrm{~km}}$, due to heterogeneities, as a function of $\sigma_{\tau_{1 \mathrm{~km}}}$ for cirrus cases 1 to 5 . We see that $\Delta D_{\text {eff, } 1 \mathrm{~km}}$ is positive and generally increases with the cirrus mean optical thickness (from cirrus cases 1 to 3 ) and the heterogeneity parameter $\rho_{\tau}$ (from cirrus cases 3 to 5). Indeed, $\sigma_{\tau_{1 \mathrm{~km}}}$ generally increases with $\tau_{\mathrm{c}}$ and $\rho_{\tau}$, as expected.
Figure 8 is the same as Fig. 5, except for different effective diameters: $D_{\text {eff }}=9.95 \mu \mathrm{m}, D_{\text {eff }}=20.09 \mu \mathrm{m}$ and $D_{\text {eff }}=40.58 \mu \mathrm{m}$ (cirrus cases 3, 6 and 7, respectively). Here $\Delta \varepsilon_{\text {eff }}$ and $\Delta \tau_{\text {eff }}$ decrease with increasing $D_{\text {eff }}$ (except at the $8.65 \mu \mathrm{m}$ band where $\varpi_{0}$ increases between $D_{\text {eff }}=9.95$ and $20.09 \mu \mathrm{m}$ ). Indeed, $\varpi_{0}$ increases with $D_{\text {eff }}$ (except at the $8.65 \mu \mathrm{m}$ band) and leads to a decrease of the absorption and, thus, of the PPA bias. The impact of the effective diameter on $\Delta \varepsilon_{\text {eff }}$ and $\Delta \tau_{\text {eff }}$ is particularly marked for the $12.05 \mu \mathrm{m}$ band where the absorption of ice crystals decreases strongly between $D_{\text {eff }}=9.95 \mu \mathrm{m}$ and $D_{\text {eff }}=40.58 \mu \mathrm{m}$ (cirrus cases 3 and 7 , respectively).

In addition, we estimated the heterogeneity effects on the retrieved ice crystal effective diameters $\left(\Delta D_{\text {eff, }} 1 \mathrm{~km}\right)$ for the three $D_{\text {eff. }}$ On average, $\Delta D_{\text {eff, } 1 \mathrm{~km}} \sim+3 \mu \mathrm{m}$ for cirrus case $3\left(D_{\text {eff }}=9.95 \mu \mathrm{m}\right)$ and $6\left(D_{\text {eff }}=20.09 \mu \mathrm{m}\right)$. Thus, there is no a significant increase of heterogeneity effects on retrieved effective diameters between these two effective sizes. For cirrus case $7\left(D_{\text {eff }}=40.58 \mu \mathrm{m}\right)$, there is no real effect ( $\Delta D_{\text {eff, } 1 \mathrm{~km}} \sim \pm 0 \mu \mathrm{m}$ ) due to the saturation of the SWT. Indeed, as noted above, effective diameters close to $40 \mu \mathrm{m}$ lead to weak brightness temperature differences. This is illustrated in Fig. 2, where the amplitude of arches, and thus the sensitivity, decreases with the increase of the effective diameter.

\subsection{Heterogeneity effects due to optical and microphysical property variabilities}

As presented in Sect. 2.2, we use the parametrization developed by Baran et al. $(2009,2013)$ and Baran (2012) to sim- 



Figure 9. Errors on the effective emissivity $\Delta \varepsilon_{\text {eff }}(\mathbf{a}, \mathbf{b}$ and $\mathbf{c})$ and on the effective optical thickness $\Delta \tau_{\text {eff }}(\mathbf{d}, \mathbf{e}$ and $\mathbf{f})$ at $8.65,10.60$ and $12.05 \mu \mathrm{m}$, respectively, as a function of the optical thickness standard deviation, $\sigma_{\tau_{1} \mathrm{~km}}$, for cirrus cases CII-1, CII-2 and CII-3.

ulate a 3-D heterogeneous cloud optical property field from the 3-D distribution of the IWC and temperature. IWC values measured during the CIRCLE-2 campaign are coupled with a MLS temperature profile to generate a realistic 3-D optical property field for simulating of the CII- 1 and CII-2 cirrus cases. In addition, to compare with the previous cirrus cases, the cirrus case CII-3 was generated from the CIRCLE2 cloud field using optical properties identical to cirrus case 8.

Figure 9 shows the impact of cirrus heterogeneities on the retrieved effective emissivity and on the effective optical thickness as a function of the standard deviation of the optical thickness, $\sigma_{\tau_{1 \mathrm{~km}}}$, for cirrus cases CII-1, CII-2 and CII-3. $\Delta \varepsilon_{\text {eff }}$ and $\Delta \tau_{\text {eff }}$ are similar for the three cirrus cases, although some slight differences are evident as a function of the wavelength. Indeed, at $8.65 \mu \mathrm{m}, \Delta \varepsilon_{\text {eff }}$ and $\Delta \tau_{\text {eff }}$ are smaller for the CII-3 cirrus case than for the two others cirrus cases. At $10.60 \mu \mathrm{m}$, this difference is close to 0 . At $12.05 \mu \mathrm{m}, \Delta \varepsilon_{\text {eff }}$ and $\Delta \tau_{\text {eff }}$ are larger for the CII-3 cirrus than for CII- 1 and CII- 2 cirrus. This effect is due to the variability of the optical properties for the CII- 1 and CII- 2 cirrus. Indeed, cirrus case CII-3 contains only aggregate crystals of effective diameter $D_{\text {eff }}=9.95 \mu \mathrm{m}$ resulting from the model of Yang et al. (2001, 2005), while cirrus cases CII- 1 and CII- 2 contain crystal of various sizes. For CII- 3 cirrus, small crystals have a singlescattering albedo maximum at $8.65 \mu \mathrm{m}$, leading to a lower PPA bias. At $12.05 \mu \mathrm{m}$, small particles are more absorbing and the PPA bias is larger. For the CII- 1 cirrus, corresponding to the cirrus observed during the CIRCLE-2 campaign, the average effective emissivity error is within the limit of the method sensibility (Garnier et al., 2012) of about 0.03 in absolute value.


Figure 10. (a) Errors on the retrieved effective diameter $\Delta D_{\text {eff, } 1 \mathrm{~km}}$ as a function of the effective diameter, $D_{\text {eff, } 1 \mathrm{~km}}^{3-\mathrm{D}}$, and (b) error on the effective optical thickness, $\Delta \tau_{\text {eff, } 1 \mathrm{~km}}$, as a function of the effective optical thickness, $\tau_{\mathrm{eff}, 1 \mathrm{~km}}^{3-\mathrm{D}}$, for cirrus CII- 1 and CII-2.

To study heterogeneity effects on the retrieved ice crystals' effective diameters for the CII-1 and CII-2 cirrus, we compare effective diameters $D_{\text {eff, } 1 \mathrm{~km}}^{3-\mathrm{D}}$ and $D_{\text {eff, } 1 \mathrm{~km}}^{1-\mathrm{D}}$ retrieved from $\mathrm{BT}_{1 \mathrm{~km}}^{3-\mathrm{D}}$ and $\mathrm{BT}_{1 \mathrm{~km}}^{1-\mathrm{D}}$, respectively. $D_{\mathrm{eff}, 1 \mathrm{~km}}^{3-\mathrm{D}}$ and $\tau_{\text {eff, } 1 \mathrm{~km}}^{3-\mathrm{p}}$ represent the cloud optical properties resulting from a 3-D radiative transfer simulation through a heterogeneous atmosphere $\left(\mathrm{BT}_{1 \mathrm{~km}}^{3-\mathrm{D}}\right)$. The differences $\Delta D_{\text {eff, } 1 \mathrm{~km}}=$ $D_{\text {eff, } 1 \mathrm{~km}}^{3-\mathrm{D}}-D_{\text {eff, } 1 \mathrm{~km}}^{1-\mathrm{D}}$ and $\Delta \tau_{\text {eff, } 1 \mathrm{~km}}=\tau_{\text {eff, } 1 \mathrm{~km}}^{3-\mathrm{D}}-\tau_{\text {eff, } 1 \mathrm{~km}}^{1-\mathrm{D}}$ correspond, therefore, to the heterogeneity effects on the retrieval of $D_{\mathrm{eff}, 1 \mathrm{~km}}^{3-\mathrm{D}}$ and $\tau_{\mathrm{eff}, 1 \mathrm{~km}}^{3-\mathrm{D}}$. For these two cirrus, the optical properties are heterogeneous. Therefore, Fig. 10a


shows $\Delta \tau_{\text {eff, } 1 \mathrm{~km}}$ as a function of $\tau_{\mathrm{eff}, 1 \mathrm{~km}}^{3-}$. We see that $\Delta D_{\text {eff, } 1 \mathrm{~km}}$ and $\Delta \tau_{\text {eff, } 1 \mathrm{~km}}$ increase, in absolute value, with 
Table 2. $\overline{D_{\text {eff,IIR }}}$ and $\overline{\tau_{\mathrm{IIR}}}$ : averaged effective diameter and optical thickness, respectively, retrieved by IIR on 25 May 2007 during the CIRCLE-2 campaign; $\overline{D_{\text {eff, } 1 \mathrm{~km}}^{3-\mathrm{D}}}$; and $\overline{\tau_{1 \mathrm{~km}}^{3-\mathrm{D}}}$ : averaged effective diameter and optical thickness, respectively, retrieved for CII-1 and CII-2 cirrus and $\overline{\Delta D_{\text {eff, } 1 \mathrm{~km}}^{3-\mathrm{D}}}$ and $\overline{\Delta \tau_{\text {eff, } 1 \mathrm{~km}}^{3-\mathrm{D}}}$ : averaged errors on the effective diameter and optical thickness, respectively, due to cloud heterogeneities in absolute value and in percentage.

\begin{tabular}{ccccccc}
\hline Cirrus & $\overline{D_{\text {eff, IIR }}}(\mu \mathrm{m})$ & $\overline{D_{\text {eff, } 1 \mathrm{~km}}^{3-\mathrm{D}}}(\mu \mathrm{m})$ & $\overline{\Delta D_{\text {eff, } 1 \mathrm{~km}}^{3-\mathrm{D}}}(\mu \mathrm{m})$ & $\overline{\tau_{\mathrm{IIR}}}$ & $\overline{\tau_{\text {eff, } 1 \mathrm{~km}}^{3-\mathrm{D}}}$ & $\overline{\Delta \tau_{\text {eff, } 1 \mathrm{~km}}^{3-\mathrm{D}}}$ \\
\hline CII-1 & 44.2 & 38.9 & $5.1(13 \%)$ & 0.41 & 0.40 & $-0.02(-5 \%)$ \\
CII-2 & - & 48.7 & $9.7(20 \%)$ & - & 0.74 & $-0.05(-7 \%)$ \\
\hline
\end{tabular}


Figure 11. Effective emissivity differences $(\mathbf{a}, \mathbf{b}, \mathbf{c})$ between $\varepsilon_{\mathrm{eff}}^{1-\mathrm{D}_{\mathrm{f}}}$ he and $\varepsilon_{\mathrm{eff}}^{1-\mathrm{D}}$ and effective optical thickness differences $(\mathbf{d}, \mathbf{e}, \mathbf{f})$ between $\tau_{\text {eff }}^{1-D_{h}}$ and $\tau_{\text {eff }}^{1-D}$ retrieved from radiances calculated in the case of vertically heterogeneous and vertically homogeneous cloudy columns, respectively, as a function of the standard deviation of the optical thickness $\sigma_{\tau_{1} \mathrm{~km}}$ for cirrus CII- 2 for bands at $8.65,10.60$ and $12.05 \mu \mathrm{m}$, respectively.

$D_{\text {eff, } 1 \mathrm{~km}}^{3-\mathrm{d}}$ and $\tau_{\text {eff, } 1 \mathrm{~km}}^{3-\mathrm{D}}$, respectively. Table 2 summarizes the optical properties retrieved by IIR during CIRCLE-2 and those retrieved from our simulations as well as the estimated heterogeneity effects. First of all, for the CII- 1 cirrus possessing the characteristics of the cirrus observed during the CIRCLE-2 campaign, the average value of the retrieved effective diameter $\left(\overline{D_{\text {eff, } 1 \mathrm{~km}}^{3-\mathrm{D}}} \sim 38.9 \mu \mathrm{m}\right)$ and the mean effective optical thickness $\left(\overline{\tau_{\text {eff, } 1 \mathrm{~km}}^{3-\mathrm{D}}} \sim 0.40\right.$ at $\left.12.05 \mu \mathrm{m}\right)$ are close to those retrieved from the IIR measurements along the CALIOP/CALIPSO track ( $D_{\text {eff, IIR }}=44.2 \mu \mathrm{m}$ and $\tau_{\mathrm{IIR}}=$ 0.41 without underlying liquid water cloud). Thus, there is a good agreement between optical properties retrieved by the IIR operational algorithm during the CIRCLE-2 campaign and those retrieved with our simulations. The mean error due to heterogeneity effects is approximately $5.1 \mu \mathrm{m}$ (13\%) for retrieved effective diameter and approximately $-0.02(5 \%)$ for effective optical thickness. On average, these relative errors due to heterogeneity effects are, thus, weak compared to the uncertainty estimate of Dubuisson et al. (2008) for the IIR retrieval (10 to $25 \%$ for $D_{\text {eff, } 1 \mathrm{~km}}$ and $10 \%$ for $\tau_{\text {eff, } 1 \mathrm{~km}}$ ).
However, at the observation pixel scale, some values can reach more than $40 \%$ for effective diameter and $15 \%$ for effective optical thickness, which is quite significant. Furthermore, errors due to cloud heterogeneities increase with the IWC or the cirrus mean optical thickness; the cirrus CII2 case, for instance, with IWC twice as large as cirrus CII1, has $\overline{\Delta D_{\text {eff, } 1 \mathrm{~km}}} \sim 9.7 \mu \mathrm{m}(20 \%)$ and $\overline{\Delta \tau_{\text {eff, } 1 \mathrm{~km}}} \sim-0.05$ (7\%).

\subsection{Influence of the vertical variability of optical properties}

To find the influence of the vertical variability of cirrus optical properties $\left(\sigma_{\mathrm{e}}, \varpi_{0}\right.$ and $g$ ) on the retrieval errors, we compare cloud products retrieved from $\mathrm{BT}_{1 \mathrm{~km}}^{1-\mathrm{D}}$ with vertically heterogeneous columns with those retrieved for vertically homogeneous columns obtained after a vertical averaging of the IWC, for the CII- 2 cirrus case.

Figures 11 shows the effects of the vertical heterogeneity of the optical properties on the effective emissivity (a, $b$ and $c$ ) and on the effective optical thickness (d, e and f). 



Figure 12. (a), (b) and (c): vertical variation of the mean extinction coefficient $\sigma_{\mathrm{e}}$; (d), (e) and (f): vertical variation of the mean singlescattering albedo $\varpi_{0} ;(\mathbf{g})$, (h) and (i): vertical variation of the asymmetry factor $g$ for the three IIR channels at $8.65,10.60 \mu \mathrm{m}$ and 12.05 for cirrus CII-2. Vertical black lines correspond to the mean value of the optical coefficient obtained after vertical averaging of the IWC.


Figure 13. Errors on the (a) retrieved effective diameter, $\Delta D_{\mathrm{eff}}^{1-\mathrm{D}}$, and (b) on the effective optical thickness, $\Delta \tau_{\mathrm{eff}}^{1-\mathrm{D}}$, as a function of $\tau_{\mathrm{eff}}^{1-\mathrm{D}}$ due to an error of $+1 \mathrm{~K}$ on the surface temperature $\left(T_{\text {surf }}+1\right)$ and $+1 \mathrm{~K}$ on the atmospheric temperature profile $\left(T_{\text {atm }}+1\right)$ for cirrus with top altitudes of $6,8,10$ and $12 \mathrm{~km}$.

Here $\varepsilon_{\text {eff }}^{1-\mathrm{D}}$ he and $\tau_{\text {eff }}^{1-\mathrm{D}}$ he are estimated from vertically heterogeneous cloudy columns and $\varepsilon_{\text {eff }}^{1-\mathrm{D}}$ and $\tau_{\text {eff }}^{1-\mathrm{D}}$ from vertically homogeneous cloudy columns, as a function of the standard deviation of the optical thickness $\sigma_{\tau_{1 \mathrm{~km}}}$ for the three IIR channels. Differences between retrieved products estimated from vertically heterogeneous and homogeneous cloudy columns are significantly weaker than those due to 3-D heterogeneities (horizontal and vertical heterogeneities). Furthermore, contrary to the 3-D heterogeneity effects $\Delta \varepsilon_{\text {eff }}$ and $\Delta \tau_{\text {eff }}$, the differences $\left(\varepsilon_{\text {eff }}^{1-D}\right.$ he $\left.-\varepsilon_{\text {eff }}^{1-D}\right)$ and $\left(\tau_{\text {eff }}^{1-D}\right.$ he $\left.-\tau_{\text {eff }}^{1-D}\right)$ are positive. These effects are particular to our simulations, where vertical heterogeneities tend thus to smooth the hor- izontal heterogeneity effects. These observations can be explained with Fig. 12, which shows the vertical profiles of the optical properties of cirrus CII-2 in the vertically heterogeneous case (red curves) and the vertically homogeneous case (black lines) after vertical averaging of the IWC and temperature using the parametrization of Baran et al. $(2009,2013)$ and Baran (2012). In this way, values of the vertically homogeneous case are different from the average of the optical coefficients of the vertically heterogeneous case: $\varpi_{0}$ of the vertically homogeneous case is larger than the vertical averaging of the heterogeneous case for the 10.60 and $12.05 \mu \mathrm{m}$ bands. In addition, the asymmetry parameter $g$ of the verti- 
Table 3. Averaged errors on the retrieved cirrus optical properties due to the 3-D cloud heterogeneity for three ice crystal effective diameters (columns 3, 4 and 5); the vertical heterogeneity of optical properties (column 6) with 1Dvhe and 1Dvho representing the -1 -D radiative transfer with vertically heterogeneous and homogeneous columns, respectively; an incertitude of $1 \mathrm{~K}$ of the surface temperature (column 7) and the temperature atmospheric profile (column 8); and the IIR retrieval uncertainty (Dubuisson et al., 2008, column 9). $\overline{\Delta D_{\text {eff }} \mathrm{km}}$ and $\overline{\left|\Delta D_{\text {eff }_{1 \mathrm{~km}} \mid}\right|}$ correspond to the absolute error in micrometers and to the relative error in percent, respectively, on the retrieval of the effective diameter; $\overline{\Delta \tau_{1 \mathrm{~km}}}$ and $\overline{\left|\Delta \tau_{1 \mathrm{~km}}\right|}$ correspond to the absolute and relative error in percent, respectively, on the retrieval of the optical thickness.

\begin{tabular}{|c|c|c|c|c|c|c|c|c|}
\hline \multirow[b]{3}{*}{$\sigma_{\tau_{1 \mathrm{~km}}}$} & \multirow[b]{3}{*}{$D_{\text {eff }}(\mu \mathrm{m})$} & \multirow{2}{*}{\multicolumn{3}{|c|}{$\begin{array}{l}\text { Horizontal heterogeneity } \\
\text { effects as a function } \\
\text { of } D_{\text {eff }}\end{array}$}} & \multicolumn{4}{|c|}{ Others uncertainties } \\
\hline & & & & & \multirow{2}{*}{$\begin{array}{c}\text { Vertical heterogeneity } \\
\text { (1Dvhe-1Dvho) }\end{array}$} & \multirow{2}{*}{$\begin{array}{c}\text { surface } \\
1 \mathrm{~K} \\
9.95\end{array}$} & \multirow{2}{*}{$\begin{array}{c}\text { atmosphere } \\
1 \mathrm{~K} \\
9.95\end{array}$} & \multirow{2}{*}{$\begin{array}{c}\text { IIR } \\
\text { uncertainty } \\
-\end{array}$} \\
\hline & & 40.58 & 20.09 & 9.95 & & & & \\
\hline \multirow[t]{4}{*}{1} & 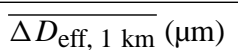 & -0.5 & 2.0 & 2.5 & 2 & 1 & 0.2 & - \\
\hline &  & $\sim 1$ & $\sim 10$ & $\sim 25$ & $\sim 4$ & $\sim 10$ & $\sim 2$ & $\sim 10$ to $\sim 25$ \\
\hline & $\overline{\Delta \tau_{\text {eff, } 1 \mathrm{~km}}}$ & -0.02 & -0.10 & -0.20 & 0.03 & 0.04 & 0.08 & - \\
\hline & $\left|\overline{\Delta \tau_{\text {eff, } 1 \mathrm{~km}}}\right|(\%)$ & $\sim 1$ & $\sim 6$ & $\sim 12$ & $\sim 4$ & $\sim 2$ & $\sim 4$ & $\sim 10$ \\
\hline \multirow[t]{4}{*}{2} & $\overline{\Delta D_{\text {eff, } 1 \mathrm{~km}}}(\mu \mathrm{m})$ & 1 & 3 & 3 & 2 & - & - & - \\
\hline & $\mid \overline{\Delta D_{\text {eff, } 1 \mathrm{~km}} \mid(\%)}$ & $\sim 3$ & $\sim 15$ & $\sim 40$ & $\sim 4$ & - & - & $\sim 10$ to $\sim 25$ \\
\hline & $\overline{\Delta \tau_{\mathrm{eff}, 1 \mathrm{~km}}}$ & -0.10 & -0.20 & -0.50 & 0.10 & - & - & - \\
\hline & $\left|\overline{\Delta \tau_{\mathrm{eff}, 1 \mathrm{~km}}}\right|(\%)$ & $\sim 6$ & $\sim 12$ & $\sim 28$ & $\sim 12$ & - & - & $\sim 10$ \\
\hline
\end{tabular}

cally homogeneous case is larger than the average of the vertically heterogeneous case in the three bands. Consequently, the cirrus is less absorbent in the vertically homogeneous case and thus the effective emissivities and effective optical thicknesses are weaker. This vertical variability of optical properties, for the cirrus CII-2 case, impact the retrieval of the effective diameter of, on average, $4 \mu \mathrm{m}$ (figure not presented here).

Note that effects of the vertical variability are discussed here for the structure of the cirrus observed during the CIRCLE-2 campaign. Effects could be different for other cirrus structure but they are not discussed here. For example, for old cirrus, sedimentation processes could be much larger, increasing differences between the cloud top and base. The impact of the vertical variability on cloud properties retrieved from satellite observations could thus be larger.

\section{Other sources of uncertainty}

We show in the previous sections that heterogeneity effects can be an important source of errors in the retrieved optical properties. To compare its importance on the retrieved cloud parameters with regard to other possible error sources for IIR measurements, we test the impact of a $1 \mathrm{~K}$ uncertainty in the surface temperature and in the atmospheric temperature profile measurements, an error that corresponds to that estimated by Garnier et al. (2012). Figure 13a and b show the error in the retrieved effective diameter $\left(\Delta D_{\text {eff }}^{1-\mathrm{D}}\right)$ and in the retrieved effective optical thickness $\left(\Delta \tau_{\text {eff }}^{1-D}\right)$, respectively, as a function of $\tau_{\text {eff }}^{1-D}$ for cirrus with a top altitude of $6,8,10$ and $12 \mathrm{~km}$. The retrieval of the effective diameter and optical thickness is performed using the SWT on 1-D radiative trans- fer simulations. We can see that $\Delta D_{\text {eff }}^{1-D}$ are less than $2.5 \mu \mathrm{m}$ $(25 \%)$ and $\Delta \tau_{\text {eff }}^{1-\mathrm{D}}$ less than $0.16(5 \%)$. By comparison, these errors are in the IIR retrieval uncertainty of 10-25\% for $D_{\text {eff }}$ and about $10 \%$ for $\tau_{\text {eff }}$ (Dubuisson et al., 2008). In addition, they are significantly smaller than those due to cloud heterogeneity effects (more than $50 \%$ for $D_{\text {eff }}$ and 10 to $15 \%$ for $\tau_{\text {eff }}$ ). In Fig. 13a, it is evident that increasing cirrus optical thickness or cloud-top altitude decreases the effective diameter retrieval error due to a $1 \mathrm{~K}$ surface-temperature uncertainty. In Fig. 13b, the effective diameter retrieval error due to atmospheric temperature profile uncertainty increases with increasing optical thickness because cloud emissivity also increases.

Fauchez et al. (2014) show that cloud-top altitude and geometrical thickness significantly influence the heterogeneity effects because the brightness temperature contrast between the surface and the cloud top increases with increasing cloudtop altitude and decreases with increasing vertical extension for a constant cloud top (as the cloud base is closer to the surface). For retrieved cloud products estimated with an algorithm similar to the IIR operational algorithm, the effective emissivity is independent of the cloud altitude and geometrical thickness; thus the impacts of altitude and geometrical thickness on the retrieval are weak.

\section{Summary and conclusions}

In this paper, we discussed the impact of cirrus heterogeneity effects in the retrieval of cloud parameters from thermal infrared radiometric measurements from space. We have focused on the IIR radiometer for which the operational algorithm estimates the cirrus effective emissivity, the effec- 
tive optical thickness and the ice crystal effective diameter of the observation pixel. We show that errors due to the cirrus heterogeneity effects on the effective emissivity and the effective optical thickness are well correlated to the subpixel optical thickness standard deviation $\sigma_{\tau_{1 \mathrm{~km}}}$ and generally increase with increasing optical thickness $\tau_{1} \mathrm{~km}$. These errors are greater than the precision of the retrieval method $\left(\Delta \varepsilon_{\text {eff }} \sim 0.03\right)$ for $\sigma_{\tau_{1 \mathrm{~km}}} \sim 1$, corresponding also to the value from which heterogeneity effects on brightness temperatures become larger than the IIR instrumental accuracy of $1 \mathrm{~K}$ (Fauchez et al., 2014).

Our results are summarized in Table 3. Heterogeneity effects for three effective diameters are compared with the retrieval errors caused by the vertical inhomogeneity of optical properties and with the impact of an error of $1 \mathrm{~K}$, corresponding to the IIR accuracy, on the atmospheric temperature profile and on the surface temperature. Results are shown for pixels with $\sigma_{\tau_{1 \mathrm{~km}}}=1$ (medium heterogeneity) and 2 (large heterogeneity). The most important errors in the cloud optical property retrieval concern those due to the subpixel heterogeneity of the optical thickness, in particular for the smallest crystals $\left(\overline{\Delta D_{\text {eff, } 1 \mathrm{~km}}}=2.5 \mu \mathrm{m}(\sim 25 \%)\right.$ and $\Delta \tau_{\text {eff } 1 \mathrm{~km}}=-0.20(\sim 12 \%)$ for $\left.\sigma_{\tau_{1 \mathrm{~km}}}=1\right)$. Indeed, the absorption is larger for small crystals and, thus, the PPA bias is greater. For $D_{\text {eff }}=40.58 \mu \mathrm{m}$, the ice crystal optical properties in the three IIR channels converge to similar values leading to smaller brightness temperature differences between channels and, thus, to a decrease of the retrieval accuracy. Errors due to the vertical inhomogeneity of the optical properties, an error of $1 \mathrm{~K}$ on the surface temperature or atmospheric temperature profile are smaller than the IIR retrieval errors (Dubuisson et al., 2008). Thus, the influence of these parameters appears negligible compared to optical thickness heterogeneity and IIR retrieval uncertainty.

The impacts of cirrus heterogeneities on the retrieved cloud parameters studied in this paper are for a $1 \mathrm{~km}$ spatial resolution. These biases could decrease with an increase of the spatial resolution although photon transport effects would increase. Fauchez et al. (2014) estimate that a $250 \mathrm{~m}$ spatial resolution could significantly reduce the PPA bias while photon transport effects remain weak. However, heterogeneity effects on the retrieved cloud products at this resolution require further investigation. This study also provides ways to potentially correct the heterogeneity errors using the subpixel measurements to estimate $\sigma_{\tau_{1 \mathrm{~km}}}$. Furthermore, differences between heterogeneity effects in the visible/nearinfrared and thermal infrared ranges for different spatial resolutions also require further investigation to estimate their impact on cloud products retrieved using a combination of the visible and near-infrared/short-wave infrared and infrared retrieval methods, as proposed by Cooper et al. (2007).
Acknowledgements. The authors acknowledge the Centre National de la Recherche Scientifique, the Programme National de Télédétection Spatiale and the Direction Générale de l'Armement for their financial support. We also thank the use of resources provided by the European Grid Infrastructure. For more information, please refer to the EGI-InSPIRE paper (http://go.egi.eu/pdnon).

We thank Anthony Baran for the numerous fruitful discussions on the cirrus optical properties.

We also thank the two reviewers whose remarks largely improved the quality of this article.

Edited by: A. Macke

\section{References}

Baran, A. J.: From the single-scattering properties of ice crystals to climate prediction: A way forward, Atmos. Res., 112, 45-69, 2012.

Baran, A. J. and Labonnote, L.-C.: A self-consistent scattering model for cirrus. I: The solar region, Q. J. Roy. Meteorol. Soc., 133, 1899-1912, 2007.

Baran, A. J., Connolly, P. J., and Lee, C.: Testing an ensemble model of cirrus ice crystals using midlatitude in situ estimates of ice water content, volume extinction coefficient and the total solar optical depth., J. Quant Spectrosc. Ra., 110, 1579-1598, 2009.

Baran, A. J., Cotton, R., Furtado, K., Havemann, S., Labonnote, L.C., Marenco, F., Smith, A., and Thelen, J.-C.: A self-consistent scattering model for cirrus. II: The high and low frequencies, Q. J. Roy. Meteorol. Soc., 140, 1039-1057, 2013.

Baum, B., Heymsfield, A., Yang, P., Platnick, S., King, M., Hu, Y.X., and Bedka, S.: Bulk scattering models for the remote sensing of ice clouds. Part 1: Microphysical data and models, J. Appl. Meteor., 44, 1885-1895, 2005a.

Baum, B., Yang, P., Heymsfield, A., Platnick, S., King, M., Hu, Y.X., and Bedka, S.: Bulk scattering properties for the remote sensing of ice clouds. Part II. Narrowband models, J. Appl. Meteor., 44, 1896-1911, 2005b.

Baum, B., Yang, P., Heymsfield, A., Schmitt, C., Xie, Y., Bansemer, A., Hu, Y.-X., and Zhang, Z.: Improvements in shortwave bulk scattering and absorption models for the remote sensing of ice clouds, J. Appl. Meteorol. Clim., 50, 1037-1056, 2011.

Cahalan, R. F., Ridgway, W., Wiscombe, W. J., Bell, T. L., and Snider, J. B.: The Albedo of Fractal Stratocumulus Clouds, J. Atmos. Sci., 51, 2434-2455, 1994.

Carlin, B., Fu, Q., Lohmann, U., Mace, J., Sassen, K., and Comstock, J. M.: High cloud horizontal inhomogeneity and solar albedo bias, J. Climate, 15, 2321-2339, 2002.

Cooper, S. J., L'Ecuyer, T. S., Gabriel, P., Baran, A. J., and Stephens, G. L.: Performance assessment of a five-channel estimation-based ice cloud retrieval scheme for use over the global oceans, J. Geophys. Res.-Atmos., 112, D04207, doi:10.1029/2006JD007122, 2007.

Cornet, C., C-Labonnote, L., and Szczap, F.: Three-dimensional polarized Monte Carlo atmospheric radiative transfer model (3DMCPOL): 3D effects on polarized visible reflectances of a cirrus cloud, J. Quant. Spectr. Radiat. Trans., 111, 174-186, 2010. 
Dubuisson, P., Giraud, V., Chomette, O., Chepfer, H., and Pelon, J.: Fast radiative transfer modeling for infrared imaging radiometry, J. Quant. Spectrosc. Ra., 95, 201-220, 2005.

Dubuisson, P., Giraud, V., Pelon, J., Cadet, B., and Yang, P.: Sensitivity of thermal infrared radiation at the top of the atmosphere and the surface to ice cloud microphysics, J. Appl. Meteorol. Clim., 47, 2545-2560, 2008.

Fauchez, T., Cornet, C., Szczap, F, Dubuisson, P., and Rosambert, T.: Impact of cirrus clouds heterogeneities on top-of-atmosphere thermal infrared radiation, Atmos. Chem. Phys., 14, 5599-5615, doi:10.5194/acp-14-5599-2014, 2014.

Field, P. R., Hogan, R. J., Brown, P. R. A., Illingworth, A. J., Choularton, T. W., and Cotton, R. J.: Parametrization of iceparticle size distributions for mid-latitude stratiform cloud, Q. J. Roy. Meteorol. Soc., 131, 1997-2017, 2005.

Field, P. R., Heymsfield, A., and Bansemer, A.: Snow size distribution parameterization for midlatitude and tropical ice clouds, J. Atmos. Sci., 64, 4346-4365, 2007.

Garnier, A., Pelon, J., Dubuisson, P., Faivre, M., Chomette, O., Pascal, N., and Kratz, D. P.: Retrieval of Cloud Properties Using CALIPSO Imaging Infrared Radiometer. Part I: Effective Emissivity and Optical Depth, J. Appl. Meteorol. Clim., 51, 14071425, 2012.

Garnier, A., Pelon, J., Dubuisson, P., Yang, P., Faivre, M., Chomette, O., Pascal, N., Lucker, P., and Tim, M.: Retrieval of Cloud Properties Using CALIPSO Imaging Infrared Radiometer. Part II: effective diameter and ice water path, J. Appl. Meteorol. Clim., 52, 2582-2599, 2013.

Hogan, R. J. and Kew, S. F.: A 3D stochastic cloud model for investigating the radiative properties of inhomogeneous cirrus clouds, Q. J. Roy. Meteorol. Soc., 131, 2585-2608, 2005.

Inoue, T.: On the temperature and effective emissivity determination of semi-transparent cirrus clouds by bi-spectral measurements in the 10- $\mu$ m window region, J. Meteorol. Soc. Jpn., 63, 88-99, 1985.

Katagiri, S., Sekiguchi, M., Hayasaka, T., and Nakajima, T.: Cirrus cloud radiative forcing at the top of atmosphere using the nighttime global distribution with the microphysical parameters derived from AVHRR, AIP Conf., Proc. 1531, 704-707, 2013.

Kato, S. and Marshak, A.: Solar zenith and viewing geometrydependent errors in satellite retrieved cloud optical thickness: Marine stratocumulus case, J. Geophys. Res.-Atmos., 114, D01202, doi:10.1029/2008JD010579, 2009.

Labonnote, C. L., Brogniez, G., Doutriaux-Boucher, M., Buriez, J.C., Gayet, J.-F., and Chepfer, H.: Modeling of light scattering in cirrus clouds with inhomogeneous hexagonal monocrystals. Comparison with in-situ and ADEOS-POLDER measurements, Geophys. Res. Lett., 27, 113-116, 2000.

Liou, K. N.: Influence of Cirrus Clouds on Weather and Climate Processes: A Global Perspective, Mon. Weather Rev., 114, 11671199, 1986.

Lynch, D. K., Sassen, K., Starr, D. O. C., and Stephens, G.: Cirrus, Oxford University Press, USA, 2002.

Magono, C.: Meteorological Classification of Natural Snow Crystals, Hokkaido University, 1966.

Marshak, A. and Davis, A. A. B.: 3D radiative transfer in cloudy atmospheres, Physics of Earth and Space Environments Series, Springer-Verlag Berlin Heidelberg, 2005.
Mayer, B.: Radiative transfer in the cloudy atmosphere, Eur. Phys. J. Conferences, 1, 75-99, 2009.

Mioche, G., Josset, D., Gaye, J. F., Pelon, J., Garnier, A., Minikin, A., and Schwarzenboeck, A.: Validation of the CALIPSOCALIOP extinction coefficients from in situ observations in midlatitude cirrus clouds during the CIRCLE-2 experiment, J. Geophys. Res.-Atmos., 115, D00H25, doi:10.1029/2009JD012376, 2010.

Nakajima, T. and King, M. D.: Determination of the optical thickness and effective particle radius of clouds from reflected solar radiation measurements. Part I: Theory, J. Atmos. Sci., 47, 1878 1893, 1990.

Parol, F., Buriez, J. C., Brogniez, G., and Fouquart, Y.: Information Content of AVHRR Channels 4 and 5 with Respect to the Effective Radius of Cirrus Cloud Particles, J. Appl. Meteorol., 30, 973-984, 1991.

Radel, G., Stubenrauch, C. J., Holz, R., and Mitchell, D. L.: Retrieval of effective ice crystal size in the infrared: Sensitivity study and global measurements from TIROS-N Operational Vertical Sounder, J. Geophys. Res.-Atmos., 108, 4281, doi:10.1029/2002JD002801, 2003.

Rienecker, M. M., Suarez, M. J., Todling, R., Bacmeister, J., Takacs, L., Liu, H.-C., Gu, W., Sienkiewicz, M., Koster, R. D., Gelaro, R., Stajner, I., and Nielsen, J. E.: Technical Report Series on Global Modeling and Data Assimilation, Technical Report, 27, 2008.

Sassen, K. and Cho, B. S.: Subvisual-Thin Cirrus Lidar Dataset for Satellite Verification and Climatological Research, J. Appl. Meteorol., 31, 1275-1285, 1992.

Sourdeval, O., Brogniez, G., Pelon, J., Labonnote, C. L., Dubuisson, P., Parol, F., Josset, D., Garnier, A., Faivre, M., and Minikin, A.: Validation of IIR/CALIPSO Level 1 Measurements by Comparison with Collocated Airborne Observations during CIRCLE2 and Biscay '08 Campaigns, J. Atmos. Oceanic Technol., 29, 653-667, 2012.

Starr, D. O. and Cox, S. K.: Cirrus Clouds. Part II: Numerical Experiments on the Formation and Maintenance of Cirrus, J. Atmos. Sci., 42, 2682-2694, 1985.

Stephens, G. L.: Radiative Properties of Cirrus Clouds in the Infrared Region, J. Atmos. Sci., 37, 435-446, 1980.

Stephens, G. L., Gabriel, P. M., and Tsay, S.-C.: Statistical radiative transport in one-dimensional media and its application to the terrestrial atmosphere, Transport Theory Stat. Phys., 20, 139-175, 1991.

Szczap, F., Isaka, H., Saute, M., Guillemet, B., and Gour, Y.: Inhomogeneity effects of 1D and 2D bounded cascade model clouds on their effective radiative properties, Phys. Chem. Earth Pt. B, 25, 83-89, 2000.

Szczap, F., Gour, Y., Fauchez, T., Cornet, C., Faure, T., Jourdan, O., Penide, G., and Dubuisson, P.: A flexible three-dimensional stratocumulus, cumulus and cirrus cloud generator (3DCLOUD) based on drastically simplified atmospheric equations and the Fourier transform framework, Geosci. Model Dev., 7, 17791801, doi:10.5194/gmd-7-1779-2014, 2014.

Varnai, T. and Marshak, A.: Statistical analysis of the uncertainties in cloud optical depth retrievals caused by three-dimensional radiative effects, J. Atmos. Sci., 58, 1540-1548, 2001.

Vaughan, M. A., Powell, K. A., Kuehn, R. E., Young, S. A., Winker, D. M., Hostetler, C. A., Hunt, W. H., Liu, Z., McGill, M. J., and Getzewich, B. J.: Fully Automated Detection of Cloud and 
Aerosol Layers in the CALIPSO Lidar Measurements, J. Atmos. Oceanic Technol., 26, 2034-2050, 2009.

Yang, P., Liou, K. N., Wyser, K., and Mitchell, D.: Parameterization of the scattering and absorption properties of individual ice crystals, J. Geophys. Res.-Atmos., 105, 4699-4718, 2000.

Yang, P., Gao, B.-C., Baum, B. A., Hu, Y. X., Wiscombe, W. J., Tsay, S.-C., Winker, D. M., and Nasiri, S. L.: Radiative properties of cirrus clouds in the infrared (8-13 um) spectral region, J. Quant. Spectrosc. Ra., 70, 473-504, 2001.
Yang, P., Wei, H., Huang, H.-L., Baum, B. A., Hu, Y. X., Kattawar, G. W., Mishchenko, M. I., and Fu, Q.: Scattering and absorption property database for nonspherical ice particles in the nearthrough far-infrared spectral region, Appl. Opt., 44, 5512-5523, 2005.

Zinner, T. and Mayer, B.: Remote sensing of stratocumulus clouds: Uncertainties and biases due to inhomogeneity, J. Geophys. Res.Atmos., 111, D14209, doi:10.1029/2005JD006955, 2006. 